Economic and Environmental Geology

\title{
Research Paper \\ Effect of Intersecting Angles of Rock Fractures on Solute Mixing at Fracture Junction
}

\author{
Dahye Kim, In Wook Yeo* \\ Department of Geological and Environmental Sciences, Chonnam National University, Gwangju 61186, Korea \\ *Corresponding author : iwyeo@chonnam.ac.kr
}

\section{ARTICLE INFORMATION}

Manuscript received 23 August 2021

Received in revised form 25 August 2021

Manuscript accepted 25 August 2021

Available online 31 August 2021

DOI : http://dx.doi.org/10.9719/EEG.2021.54.4.465

\section{Research Highlights}

- Solute mixing at fracture junction depends on fluid velocity and intersecting angle.

- A decrease in fluid velocity and intersecting angle leads to complete solute mixing.

- An increase in fluid velocity and intersecting angle yields streamline-routing.

\begin{abstract}
This numerical study aims at analyzing the effect of flow characteristics, caused by geometrical features such as intersecting angles, on solute mixing at fracture junctions. It showed that not only $P e$, the ratio of advection to diffusion, but also the intersecting angles played an important role in solute mixing at the junction. For the intersection angles less than $90^{\circ}$, the fluid flowed to the outlet in the same direction as the injected flow direction, which increased the contact at the junction with the streamlines coming from the different inlets. On the other hand, for the intersecting angles greater than $90^{\circ}$, the fluid flowed out to the outlet opposite to the flow direction in the inlet, leading to minimizing the contact at the junction. Therefore, in the former case, solute mixing occurred even at high $P e$, and in the latter case, solutes transport along the streamlines even at low $P e$. For $P e<1$, the complete mixing model was known to occur, but for the intersecting angle greater than $150^{\circ}$, no complete solute mixing occurred. Overall, the transition from the complete mixing model to the streamline-routing model occurred for $P e=0.1-100$, but it highly depended on the intersecting angles. Specifically, the transition occurred at $P e=0.1-10$ for intersecting angles $\geqq 150^{\circ}$ and at $P e=10-100$ for intersecting angles $\leqq 30^{\circ}$. For $P e>100$, the streamline-routing model was dominant regardless of intersecting angles. For $P e>1,000$, the complete streamlinerouting model appeared only for the intersecting angles greater than $150^{\circ}$. For the intersecting angles less than $150^{\circ}$, the streamlinerouting model dominated over the complete solute mixing, but solute mixing still occurred at the fracture junction.
\end{abstract}

Keywords : rock fractures, fracture junction, intersecting angle, complete mixing model, streamline-routing model

Citation: Kim, D., Yeo, I.W. (2021) Effect of Intersecting Angles of Rock Fractures on Solute Mixing at Fracture Junction. Korea Economic and Environmental Geology, v.54, p.465-473, doi:10.9719/EEG2021.54.4.465.

This is an Open Access article distributed under the terms of the Creative Commons Attribution Non-Commercial License (http://creativecommons.org/ licenses/by-nc/3.0) which permits unrestricted non-commercial use, distribution, and reproduction in any medium, provided original work is properly cited. pISSN 1225-7281; eISSN 2288-7962/@2021 The KSEEG. Printed by Hanrimwon Publishing Company. All rights reserved. 


\section{연구논문}

\section{암반단열의 교차각이 교차점에서의 용질의 혼합에 미치는 영향}

김다혜 · 여인욱*

전남대학교 지질환경과학과

*책임저자 : iwyeo@chonnam.ac.kr

\section{요 약}

본 연구에서는 수치모델링을 통해 단열의 교차각과 같은 기하학적 특징이 교차점에서의 유동특성과 용질의 혼합.분배에 미치

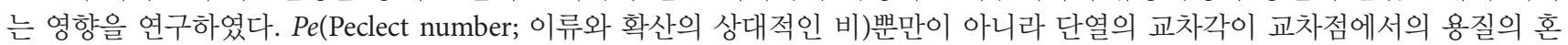
합.분배모델을 결정하는데 있어 중요한 역할을 하는 것으로 나타났다. 교차각이 $90^{\circ}$ 미만인 경우, 주입된 유동방향과 동일한 방 향의 유출구로 진행하기 때문에 교차점에서 양쪽 주입구에서 온 유선들의 접촉을 용이하게 한다. 반면, 교차각이 $90^{\circ}$ 보다 큰 경 우 유체가 주입된 유동방향과 유출구의 방향이 반대이기 때문에, 교차점에 두 주입구에서 온 유선들 간의 접촉은 최소화 되었 다. 그러므로 전자의 경우에서는 높은 $P e$ 에서도 용질의 혼합이, 후자에서는 낮은 $P e$ 에서도 유선경로에 따른 용질의 이동이 나 타났다. 따라서 $P e<1$ 의 경우, 완전혼합모델이 지배적인 것으로 알려졌지만, 교차각이 $150^{\circ}$ 인 경우 교차점에서 혼합뿐만이 아 니라 일부는 유선의 경로를 따라 유출구로 유출되었다. 전반적으로 $P e$ 가 $0.1-100$ 에서 완전혼합모델에서 유선경로모델로의 전 이가 나타났지만, 이는 교차각에 따라 크게 달라진다. 교차각이 클수록 $\left(\geqq 150^{\circ}\right) P e$ 가 $0.1-10$ 에서, 교차각이 작을수록 $\left(\leqq 30^{\circ}\right) P e$ 가 $10-100$ 에서 전이가 발생하였다. $P e>100$ 에서는 교차각과 상관없이 유선경로모델이 더 지배적인 것으로 나타났다. $P e>$ 1,000 에서는 교차각이 $150^{\circ}$ 이상인 경우에만 $100 \%$ 유선경로모델이 나타나며, 교차각이 $150^{\circ}$ 미만인 경우 유선경로모델이 지배적 이지만 여전히 교차점에서 용질의 혼합이 발생하였다.

주요어 : 암반단열, 단열 교차점, 교차각, 완전혼합모델, 유선경로모델

\section{1. 서 론}

지중 암반에 건설되는 방사성 폐기물 심지층 처분, 에 너지 지중저장 및 석유 비축기지 등과 같은 시설물들은 저장물이 외부로 유출되지 않도록 오랫동안 안전하게 보 관해야하기 때문에 상대적으로 투수성이 작은 암반층에 건설된다(Blessent et al., 2011; Dessirier et al., 2015; Tsang et al., 2015). 또한 우리나라와 같이 토양층이 얕은 경우 지하수가 오염되면 암반까지 오염될 수 있다. 암반의 경 우 토양과 달리, 지하수 유동과 용질의 이동이 특정한 불 연속적인 단열들을 통해 일어나기 때문에, 단열의 기하 학적인 발달 상태에 따라 지하수의 유동특성이 크게 달 라질 수 있다. 따라서 단열과 단열 망(fracture network) 에서 지하수의 유동과 용질의 이동 특성들을 이해하는 것은 매우 중요하다.

단열 망 규모에서의 지하수 유동과 용질이동에 대한 이 해는 단일 단열에서의 유동특성과 그에 따른 용질 이동 기작을 이해하는 데부터 시작된다. 단일 단열을 통한 유 동에 대한 연구들은 유량의 정량화와 Stokes 식, Reynolds 식(local cubic law), cubic law와 같은 선형방정식의 적용 과 그 한계에 대한 연구에 초점이 맞춰져 있다(Brush and
Thomson, 2003; Ji et al., 2008; Lee et al., 2010; Lee et al., 2014; Oron and Berkowitz, 1998; Zhou et al., 2015; Zimmerman et al., 2004; Zimmerman and Yeo, 2000). 단 일 단열 내에서의 용질의 거동 대한 연구는 유속에 따른 분산특성이나 농도이력곡선에 나타나는 테일링(tailing) 현상을 규명하는데 초점이 맞춰지고 있다(Boutt et al., 2006; Cardenas et al., 2007, 2009; Detwiler et al., 2000; Lee et al. 2015; Neretnieks et al., 1982).

하지만, 단열 망 규모, 특히 단열 교차점(fracture junction) 에서의 지하수 유동특성과 그에 따른 용질의 혼합과 분 배에 대한 연구는 상대적으로 부족하다. 단열 교차점에 서는 교차각에 따라 기하학적 특성이 크게 달라지기 때 문에 유체의 유동이 달라지며 그로 인해 용질의 혼합.분 배 특성 역시 단일 단열과는 다르다. 단열 교차점에서의 용질의 혼합·분배는 완전혼합(complete mixing)모델과 유 선경로(streamline-routing)모델로 분류된다(Berkowitz, 1994; Stockman et al., 1997; Park and Lee, 1999).

Fig. 1은 교차점에서의 완전혼합모델과 유선경로모델에 따른 용질의 혼합.분배 과정의 차이를 보여준다. 이때 유 체(지하수)는 inlet 1 과 2 를 통해 유입되며, 일정 농도를 가진 유체는 inlet 1 만을 통해 주입되었을 때를 고려한다. 


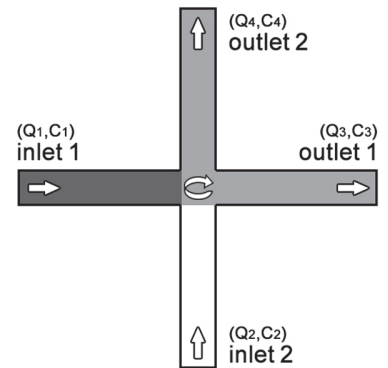

(a)

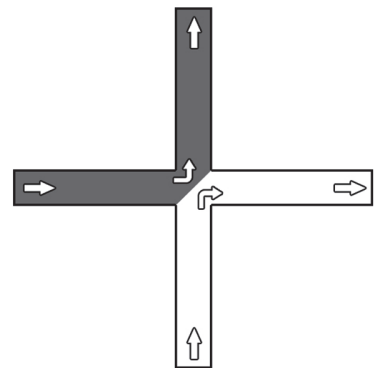

(b)
Fig. 1. Mixing characteristics models at fracture intersection: (a) complete mixing model and (b) streamline-routing model (after Park and Lee, 1999).

완전혼합모델은 단열 교차점에서 합류한 두 용액이 완전 히 혼합되어 동일한 농도로 분배된다는 이론으로서, 지 하수 유속이 느릴 때 교차점 내에서 용질의 체류시간이 길어짐에 따라 일어난다(Fig. 1a). 반면, 유선경로모델은 교차점에서의 유선 경로에 비례하여 용질의 배분이 일어 난다는 물리적 모델이다(Fig. 1b). 단열 교차점에서 두 혼 합·분배 모델의 비중은 혼합 비율(mixing ratio, $M_{r}$ )로 분 석하며, 완전혼합모델의 경우 $M_{r}$ 은 0.5 , 유선경로모델의 경우 $M_{r}$ 은 0 에 해당된다. $M_{r}$ 은 outlet 1 과 2 로 빠져나가 는 유체의 유량 $\left(Q_{3}, Q_{4}\right)$ 과 농도 $\left(C_{3}, C_{4}\right)$ 를 이용하여 산정 할 수 있다(Stockman et al., 1997).

$$
M_{r}=\frac{Q_{3} C_{3}}{Q_{3} C_{3}+Q_{4} C_{4}}
$$

$M_{r}$ 은 이류와 확산의 상대적인 비를 나타내는 페클렛 수(Peclet number, $P e$ )에 민감하게 영향을 받는다. 여기서 $P e$ 은 $u e / D_{m}$ 로서 $u$ 는 유속의 크기, $e$ 는 단열의 간극, $D_{m}$ 은 확산계수이다. 즉, $P e$ 가 점차 증가함에 따라 확산보다는 이류에 의한 용질이동이 커지기 때문에, 완전혼합모델보 다는 유선경로모델이 지배적인 혼합·분배 모델이 된다.

$M_{r}$ 을 이용하여 $P e$ 에 따른 두 혼합·분배 모델의 전이과 정을 분석하기 위한 다양한 이론적(Mourzenko et al., 2002; Park et al., 2001; Park and Lee, 1999), 수치적(Berkowitz, 1994; Li, 1995; Stockman et al., 1997; Zafarani and Detwiler, 2013), 실험적(Li, 1995) 연구들이 수행되었다. Fig. 2는 평행한 단열이 $90^{\circ}$ 로 교차하는 경우에 대한 이 전의 연구결과들을 정리한 그림이다. Li (1995)는 LGA (Lattice Gas Automaton) 기법을 적용한 수치적 연구와 더불어 단열 교차점 모형을 제작하여 실험연구를 함께 진행하였다. 그 결과, $P e<0.68$ 에서는 완전혼합모델을 따르고, $P e=1-10$ 에서 유선경로모델로의 전이가 발생 하였다. Stockman et al. (1997)은 $P e=0-1,547$ 범위에

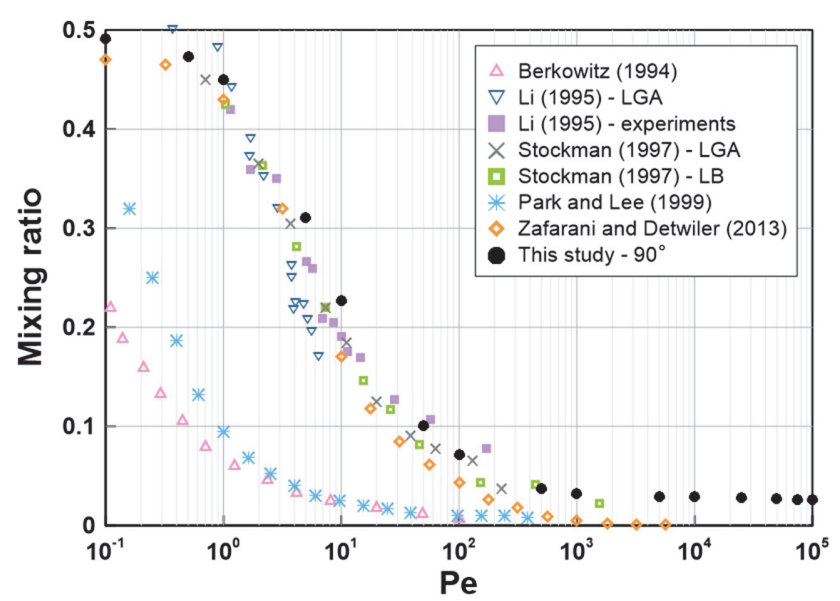

Fig. 2. Summarized plots of mixing ratio $\left(M_{r}\right)$ versus $P e$ for the case of an intersecting angle of $90^{\circ}$, using previous studies and this study.

서 LGA 및 LB (Lattice Boltzmann) 방법을 적용하여 수 치모델링 수행하였으며, $P e=1-100$ 에서 완전혼합모델 에서 유선경로모델로 점진적인 전이가 발생하였다. 또한 $P e>1,000$ 에서도 $M_{r}$ 이 0 으로 수렴하지 않아 $100 \%$ 유선 경로모델을 따르지 않는다는 결과를 제시하였다. 반면, Zafarani and Detwiler (2013)의 시간 영역 접근법(timedomain approach)을 도입한 수치해석 연구 결과, $\mathrm{Pe}>$ 1,000 에서 $M_{r}=0$ 으로 수렴한다는 상반된 결과를 제시 하였다. Berkowitz (1994)의 무작위 보행 입자추적 방법 (random-walk particle-tracking method)을 이용한 수치적 연구와 Park and Lee (1999)의 분석적 연구 모두, 앞선 결과와 달리 $P e<0.1$ 에서도 완전혼합모델을 따르지 않 고 유선경로모델로의 전이가 상대적으로 낮은 $P e$ 의 범위 에서 발생하였다.

기존의 연구결과들은 $P e<1, P e>1,000$ 영역에서 상 이한 결과를 제시하고 있어 추가적인 연구의 필요성을 보여준다. 또한 앞선 연구들은 단열이 $90^{\circ}$ 로 교차하는 가 장 단순한 경우를 가정하여 수행되었기 때문에 다양한 교차각을 갖는 암반 단열에 적용하는데 그 한계가 있다. 또한 $P e$ 의 범위가 대부분 1,000 이하여서, 빠른 유속조건 에서 발생할 수 있는 비선형 유동영역에서의 용질의 분 배 특성을 반영할 수가 없다. 비선형 유동 영역에서는 교 차점의 기하학적 특성에 따라 소용돌이(eddy)와 같은 유 동구조가 발생하여 용질의 혼합·배분이 달라질 수 있다. 따라서 본 연구에서는 비선형 유동영역까지 포함하는 넓 은 $P e$ 범위와 다양한 교차각을 갖는 단열 교차점에 대한 연구를 수행하여, 실제 암반 단열의 기하학적 특성과 지 하수의 유속 조건에 따라 발생할 수 있는 용질의 혼합. 분배 특성을 연구하고자 하였다. 


\section{2. 연구 방법}

본 연구에서는 수치모델링을 통해 단열 교차점에서의 용질의 혼합·분배를 분석하였다. 수치모델링은 상업용 소 프트웨어인 COMSOL Multiphysics를 사용하였으며 (COMSOL AB, 2019), 먼저 정상류 조건에서 단열 교차 점에서의 지하수의 유속분포를 계산하였다. 정상류 조건 에서 단열을 통한 비압축성 유체의 흐름은 다음의 NavierStokes 방정식으로 기술할 수 있다(Zimmerman and Yeo, 2000).

$$
\rho(\mathbf{u} \cdot \nabla) \mathbf{u}=\mu \nabla^{2} \mathbf{u}-\rho g \nabla h
$$

여기서 $\rho$ 는 밀도, $g$ 는 중력가속도, $\mathbf{u}$ 는 속도 벡터, $\mu$ 는 점성도, $h$ 는 수두에 해당한다. 유체의 온도와 밀도는 일 정하다고 가정하였으며, 점성도는 물의 점성도인 $1 \times 10^{-3}$ $\mathrm{Pa} \cdot \mathrm{s}$ 를 사용하였다. 단열을 통한 용질의 이동방정식은 다 음과 같다(Bear et al., 1993).

$$
\frac{\partial C}{\partial t}+\mathbf{u} \cdot \nabla C-\nabla \cdot D(\nabla C)=0
$$

여기서 $C$ 는 용질의 농도, $t$ 는 시간, $D$ 는 용질의 확산 계수이다. 확산계수는 용질이동 실험에 추적자로 자주 사 용되는 Rhodamine B의 확산계수인 $3.6 \times 10^{-10} \mathrm{~m}^{2} / \mathrm{s}$ 를 사 용하였으며, 식 (3)의 $\mathbf{u}$ 는 식 (2)에서 구한 유속을 사용 하였다.

$0.5 \mathrm{~mm}$ 의 간극과 $10 \mathrm{~mm}$ 의 길이를 갖는 두 개의 단열 이 교차하는 경우를 고려하여 2차원 수치모델링을 수행 하였으며, 단열은 거칠기(roughness)가 없는 평행한 단열 (parallel-walled fracture)을 가정하였다. 단열의 교차각은 inlet 1 과 2 의 사이 각으로 정의하였으며(Fig. 3), $30^{\circ}, 60^{\circ}$, $90^{\circ}, 120^{\circ}, 150^{\circ}$ 로 교차하는 경우를 고려하였다. 유체는 지하수를 고려하였다.

본 연구에서는 비선형 유동영역까지 유속조건을 확장 하여 용질의 혼합·분배 모델을 검토하였다. 가해진 수두 구배와 유출되는 유량간의 선형적 관계에서 벗어나는 비 선형 유동의 발생 유무는 점성력에 대한 관성력의 상대 적인 비를 나타내는 레이놀즈수(Reynolds number, $R e$ )를 이용하여 설명할 수 있다. 여기서 $R e$ 은 $\rho u e / \mu$ 이며 $\mu$ 는 점성계수이다. 기존 연구에 따르면, 단일 단열의 비선형 유동영역은 $R e=10$ - 20에서 발생하는 것으로 알려졌다 (Ji et al., 2008; Zhang and Nemcik, 2013; Zimmerman and Yeo, 2000; Zimmerman et al., 2004; Zhou et al., 2015). 따라서 본 연구에서는 $R e=3.6 \times 10^{-5}-36$ 의 범위에서 지하수 유동 모델링을 수행하여 단열 교차점의 기하학적

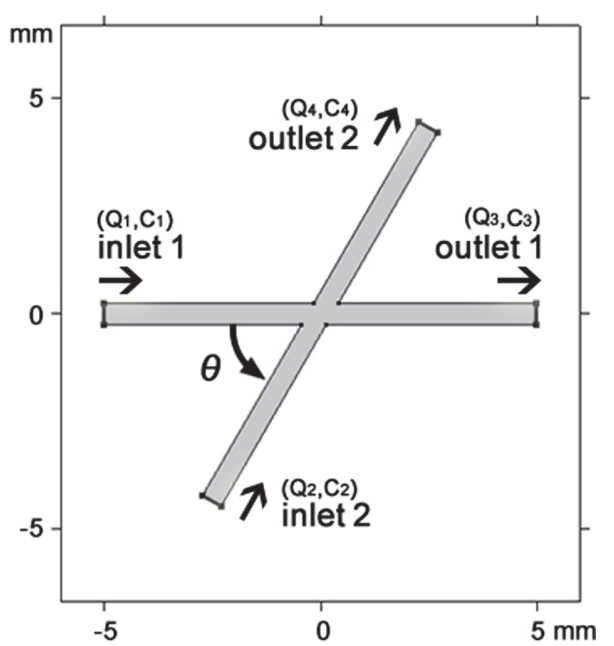

Fig. 3. Geometrical features of the fractures that intersect at $30^{\circ}$, $60^{\circ}, 90^{\circ}, 120^{\circ}$ and $150^{\circ}$. An intersecting angle $\theta$ is defined as an anticlockwise angle from inlet 1 . Water is injected through inlets 1 and 2 at the same flow rate, but water at inlet 1 has a concentration of $1 \mathrm{~mol} / \mathrm{m}^{3}$.

특성에 따라 발생하는 유동특성을 분석하였다.

단열 교차점에서 용질의 혼합·분배를 분석하기 위하여 inlet 1 의 끝에만 농도를 일정하게 주입하였으며(즉 $C_{1}=$ $\left.1, C_{2}, C_{3}, C_{4}=0 \mathrm{~mol} / \mathrm{m}^{3}\right)$, 용질 이동 모델링을 수행하였 다. 유속조건은 지하수 유동모델링과 같은 $R e=3.6 \times$ $10^{-5}-36$ 이며, 이 범위는 $P e=0.1-100,000$ 에 해당이 된다. Outlet 1과 2에서 측정된 유량과 농도를 이용하여 $M_{r}$ 을 산정하여 교차점에서의 용질의 혼합·분배 특성을 분석하였다.

\section{3. 연구 결과}

Fig. 4는 $R e=0.000036$ - 36에서 계산된 대표적인 유 속의 분포와 유선을 보여준다. Intel 1과 2에서 동일한 유 속으로 주입되었기 때문에, 교차각과 $R e$ 와 상관없이 inlet 1,2 로 주입된 유체는 각각 outlet 2 와 1 로 각각 유출되었 다. 교차각이 $30^{\circ}$ 인 경우, 주입된 유체의 유동방향과 유 출구의 방향과 일치하기 때문에, 양쪽 주입구에서 온 유 선이 교차점에서 겹치면서 유속이 가장 큰 구간이 넓게 형성된다(Fig. 4). 단열 교차각이 커지면서 유속이 가장 큰 구간의 면적은 점차적으로 감소하였다. 특히 교차각 이 $90^{\circ}$ 를 초과할수록, 유체는 교차점에서 주입된 유체의 유동방향과 반대인 유출구로 유출되기 때문에 교차점에 서 오히려 유속이 가장 작은 구간이 넓게 형성된다. 교 차각에 따른 교차점에서의 유동특성의 분명한 차이는 교 차점에서의 용질의 혼합과 분배에 중요한 역할을 할 것 으로 판단된다. 


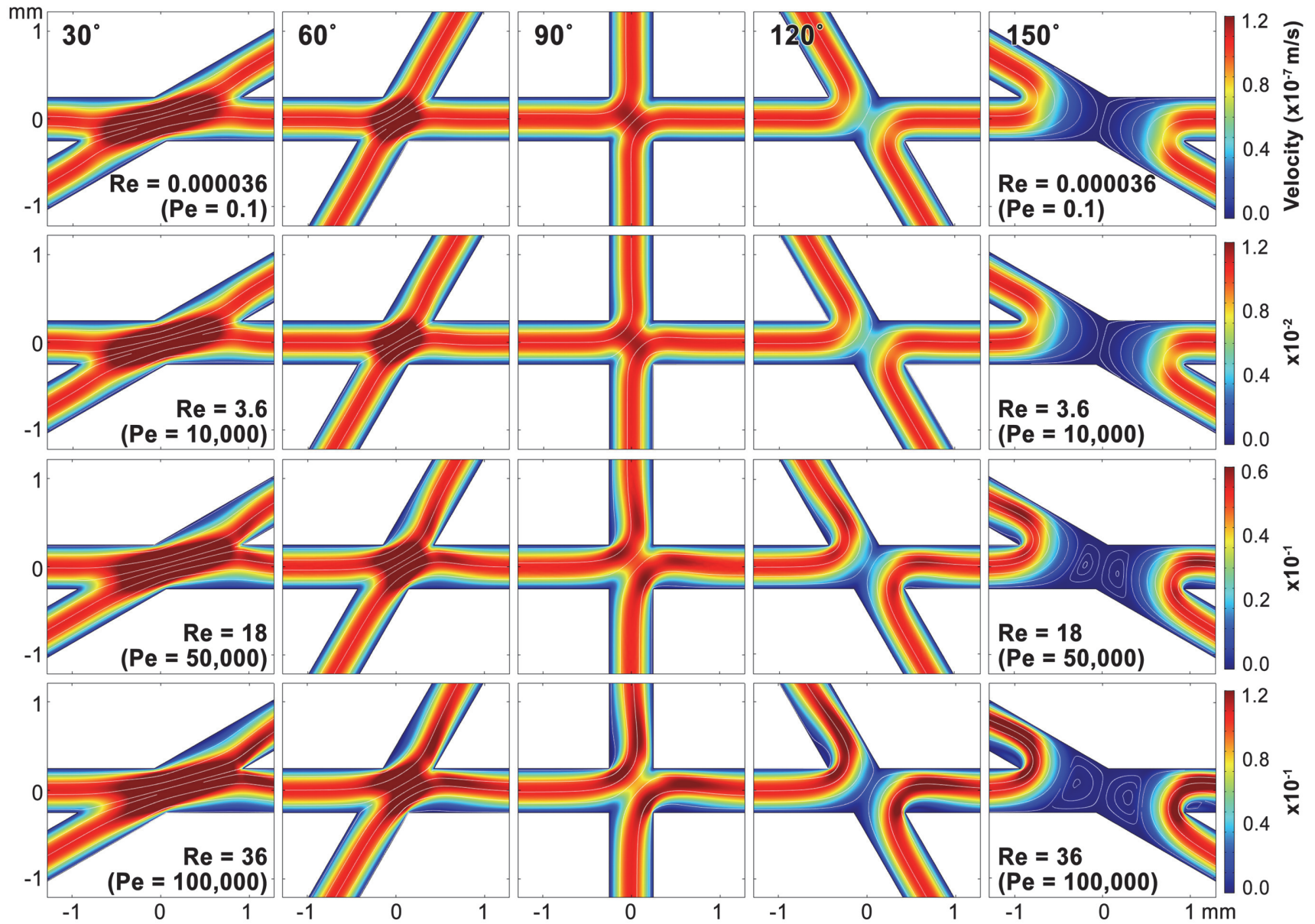

Fig. 4. Plots of streamlines and velocity magnitudes at the fracture junctions for $\mathrm{Pe}=0.1,10,000,50,000,100,000$.

$R e \geqq 18$ 에서 유선이 단열 교차점에서 더 크게 휘어지 며, 유속이 가장 큰 위치도 유출구 쪽까지 더 넓게 나타 났다(Fig. 4). 이는 유속이 증가하면서 점성력에서 관성 력이 지배적인 유동시스템으로 바뀌고 있음을 의미한다. 또한 단열이 $150^{\circ}$ 로 교차하는 경우, $R e=18$ 부터 단열의 교차점에 형성된 저속도 구간에서 소용돌이 구조가 발달 하기 시작했다. Chaudhary et al. (2011)는 비선형 유동의 발생기작을 소용돌이 구조의 발생과 성장으로 설명하였 다. 이러한 유선의 변화와 소용돌이 구조는 약 $R e \geqq 18$ 에서 선형 유동영역에서 비선형 유동영역으로 전이되었 을 가능성을 시사한다.

Zimmerman et al. (2004)은 주입유량의 증가에 따른 투 수량계수의 상대적인 변화를 비교하여 비선형 유동의 발 생 시점을 분석하였다. 단열을 통한 지하수 유동은 단열 간극(aperture)의 3승에 비례하는 cubic law로 표현할 수 있다(Zimmerman and Yeo, 2004).

$$
Q=\frac{\rho g e_{h}^{3} w}{12 \mu} \frac{d h}{d x}
$$

여기서 $Q$ 는 유량, $w$ 는 단열의 폭이고, $e_{h}$ 는 수리간극 (hydraulic aperture)이다. 각 유속조건에서 유출구로 유출 되는 유량과 주입구와 유출구의 수두차를 이용하여 수리 간극을 계산한 후 아래의 식으로 투수량계수(transmissivity, T)를 산출하였다.

$$
T=\frac{\rho g e_{h}^{3}}{12 \mu}
$$

$R e$ 가 가장 작은 조건에서 계산된 투수량계수를 $T_{0}$ 로 정 의하여, 투수량계수의 상대적인 변화 $\left(T / T_{0}\right)$ 를 계산하였다 (Fig. 5). $T / T_{0}$ 비는 단열이 교차하는 각도와 상관없이 $R e$ $>10$ 에서 급격하게 감소하기 시작하였다. $R e<18$ 까지 단열 교차각과 상관없이 $T / T_{0}$ 비는 동일하였으나, $150^{\circ}$ 로 교차하는 경우 $R e=18$ 부터 다른 교차각에 비해 $T / T_{0}$ 비 의 감소가 더욱 두드러졌다. 이는 교차점 중심부에서 크 게 발달하는 소용돌이 구조가 비선형 유동영역을 더 가 속화시켰음을 시사한다.

Zimmerman et al. (2004)은 $T / T_{0}=0.9$ 일 때의 $R e$ 를 비 


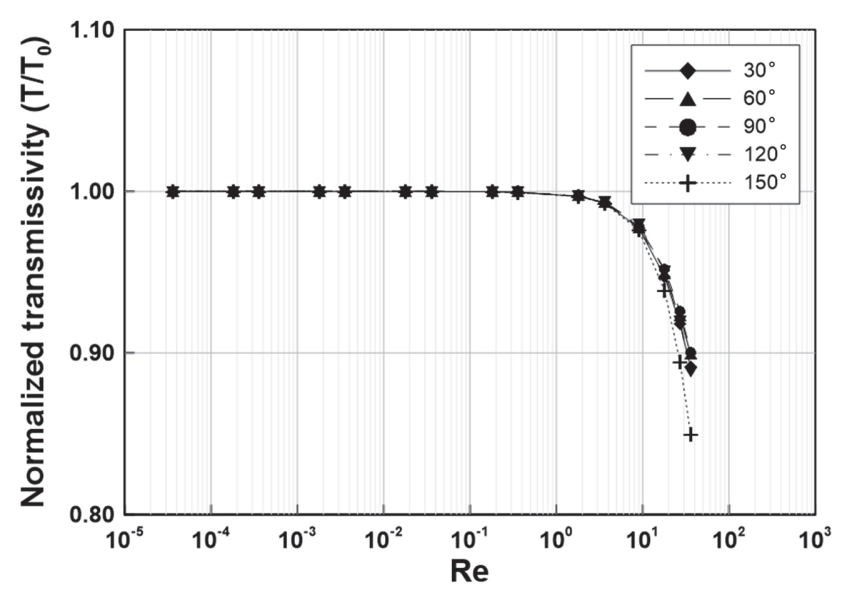

Fig. 5. Normalized transmissivity change as a function of Reynolds number for various intersecting angles.

선형 유동이 시작하는 임계 $R e$ 로 제시하였다. 따라서 10 $<R e<30$ 에서 전이유동영역(transitional flow regime)이, 그리고 $R e>30$ 에서 비선형 유동이 나타나는 것으로 판 단하였다. 이는 Zimmerman et al. (2004)이 단일 단열에 대해 제시한 임계 $R e=20$ 과 매우 유사하다. 교차하는 두 개의 단열이 모두 평평함에도 불구하고, 거친 단일 단 열(rough-walled single fracture)과 유사한 $R e$ 에서 비선형 유동영역이 발생하는 것은 단열 교차점의 기하학적 특징 이 단일 단열의 거칠기 효과와 유사하기 때문인 것으로 판단된다.

단열 교차점에서의 용질의 혼합·분배 특성을 분석하기 위하여 inlet 1 에만 일정한 농도 $\left(C_{1}=1 \mathrm{~mol} / \mathrm{m}^{3}\right)$ 를 갖는 지하수를 연속적으로 주입하며 용질이동모델링을 수행하 였다. $P e=0.1$ 일 때, 단열의 교차각이 $120^{\circ}$ 미만인 경우 inlet 1과 2로 부터 유입된 지하수가 교차점에서 완전히 혼합(mixing)되어 유출구로 유출되었다(Fig. 6). 또한 $C_{2}$ $=0$ 인 inlet 2 의 단열 쪽에도 농도가 관찰된다. $P e<1$ 에 서는 이류보다는 확산에 의한 용질의 이동이 지배적으로 일어나며, 그로 인해 교차점에서 혼합된 용질이 inlet 2 방 향으로도 확산되기 때문이다. $P e=1$ 의 경우 단열 교차 점에서 용질의 혼합과 더불어 교차각에 따라 유선을 따 라 용질이 이동하는 특징이 나타난다. 특히 단열의 교차 각이 클수록 유선을 따라가는 용질의 이동이, 교차각이 작을수록 유체의 혼합이 더 발생하였다. 이는 Fig. 4에서 관찰된 것처럼, 단열이 교차하는 각도가 작을수록 inlet 1 과 2로 주입된 유체의 유선이 상대적으로 넓게 접하며 혼합이 잘 이루어지기 때문이다.

$P e$ 가 10 으로 증가함에 따라 교차점에서 용질의 혼합정 도가 급격히 감소하였다. 이는 확산보다 이류에 의한 용 질이동이 우세해지면 용질이 유선을 따라 이동되기 때문
이다. $P e$ 가 100 을 넘어서면서부터 용질은 거의 혼합되지 않고 각각 outlet 2 와 1 로 분리되어 유출되었다. 혼합되 는 정도는 교차각이 커질수록 작아졌다. $P e=10,000$ 일 때, 단열의 교차각이 $90^{\circ}$ 미만인 경우 교차점에서 일부 혼 합이 발생하며 주입구와 다른 유선인 outlet 1 으로 유출 되었다. 교차각이 $90^{\circ}$ 를 초과하는 경우 혼합이 거의 이 루어지지 않고 유선을 따라 outlet 2 로 유출되었다. 이는 Fig. 4에서 보듯이 단열이 교차각이 클 때 교차점에서 유 속이 작은 구간이 발달하게 되며, 이로 인해 교차점에서 용질의 혼합이 일어나기 어렵기 때문이다. $P e=100,000$ 일 때, 교차각이 $150^{\circ}$ 인 경우 교차점에 발생한 소용돌이 로 인해 용질이 갇혀 교차점에 체류하는 현상이 관찰되었다.

$P e$ 에 따라 용질의 혼합정도를 정량적으로 분석하기 위 하여 $M_{r}$ 을 계산하였다. 동일한 $P e$ 에서 단열의 교차각에 따른 $M_{r}$ 을 비교한 결과, 단열의 교차각이 클수록 $M_{r}$ 이 작게 나타났다(Fig. 7). $P e=0.1$ 일 때, 교차각이 $90^{\circ}$ 이하 인 경우 $M_{r}$ 은 약 0.5 로 완전혼합모델을 따른 반면, 교차 각이 $120^{\circ}, 150^{\circ}$ 인 경우 $M_{r}$ 은 $0.473,0.423$ 으로 감소하였 다. 심지어 $P e=0.1$ 에서도 교차각이 큰 경우 완전혼합 이 발생하지 않는 것을 의미한다.

$P e$ 가 0.1 - 100에서 완전혼합모델에서 유선경로모델로 전이되었지만, 이는 교차각에 따라 크게 달라진다. 교차 각이 $150^{\circ}$ 이상인 경우 $P e=0.1-10$ 에서, 교차각이 $30^{\circ}$ 이하인 경우 $P e=10-100$ 에서 완전혼합에서 유선경로 모델로의 전이가 발생하였다. 이는 Fig. 6에서 보듯이 단 열의 교차각이 클수록 유체의 혼합이 감소하기 때문이다. $P e>100$ 인 경우 유선경로모델이 지배적이며, $P e>1,000$ 의 경우 교차각과 상관없이 $M_{r}$ 이 일정한 값으로 수렴하 였다. 단열이 $150^{\circ}$ 로 교차하는 경우를 제외하고 $M_{r}$ 값이 0 으로 수렴하지 않았으며, 교차각이 작을수록 수렴 값은 크다. 교차각이 $30^{\circ}$ 인 경우 용질의 혼합이 여전히 발생 하며, 이로 인해 용질의 약 $10 \%$ 는 용질이 주입된 유선과 다른 단열로 유출되는 것으로 나타났다. 이는 Fig. 6에서 보듯이, 교차각이 작을수록 inlet 1과 2에서 들어온 유선 들 간의 접촉 면적이 커지면서 일부 혼합이 일어나고 그 로 인해 용질이 다른 유선으로 이동하기 때문이다.

$R e=10(P e=27,778)$ 부터 유동영역의 전이가 발생하 고, $R e=30(P e=83,333)$ 부터는 비선형 유동이 발생했 음에도 불구하고 $P e=100,000$ 까지 혼합비율의 큰 변화 는 없었다. 유동 영역의 변화와 소용돌이와 같은 유동구 조의 변화가 교차점에서의 용질의 혼합·분배에 미치는 영 향이 크지 않았다.

단열이 $90^{\circ}$ 로 교차하는 경우에 대해, 본 연구의 결과와 기존 연구결과를 비교하였다(Fig. 2). 본 연구 결과, $P e<$ 1 일 때 완전혼합모델을 따르지만, $P e=1-100$ 에서 완 


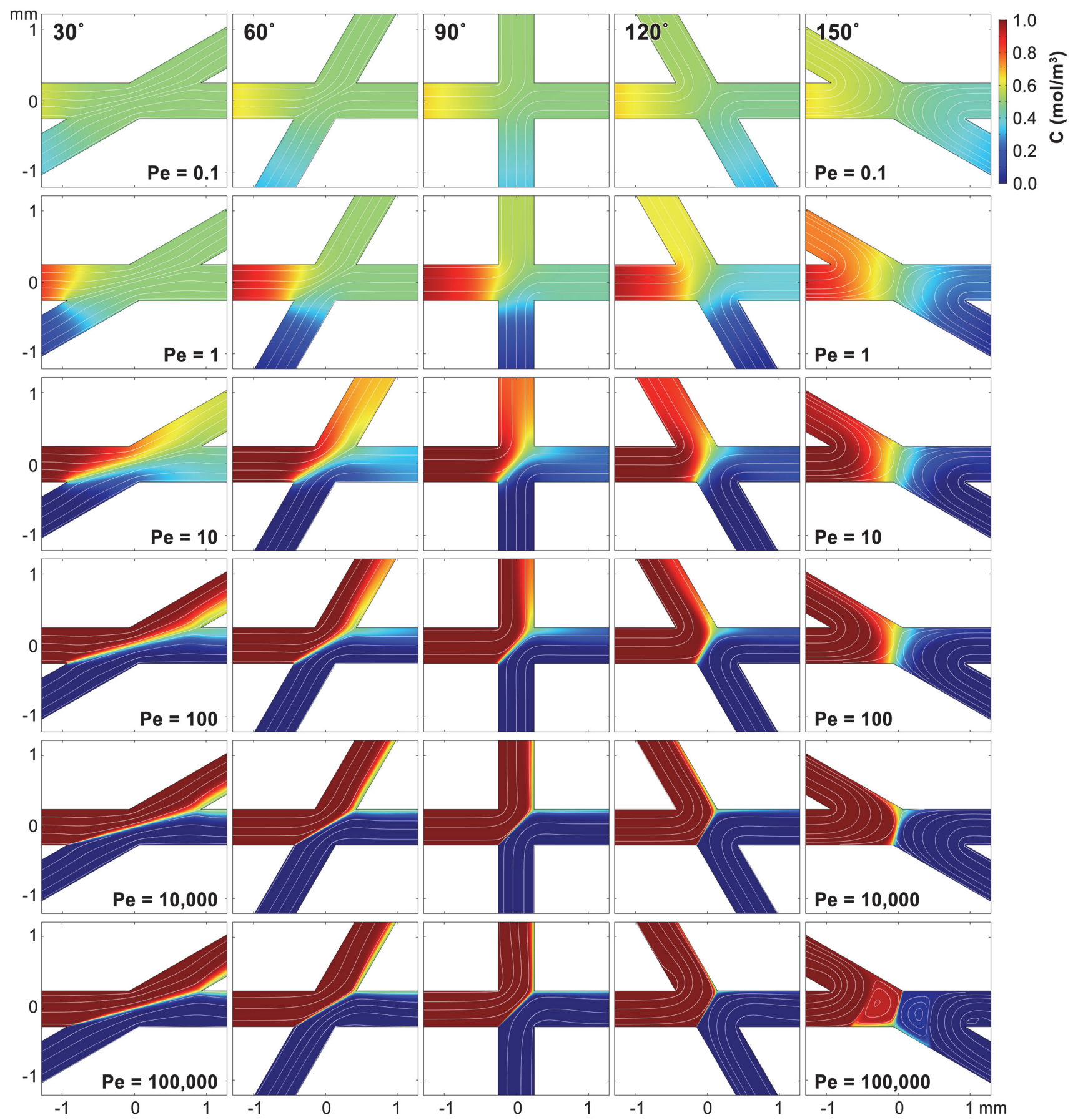

Fig. 6. Concentration contours at the fracture junctions for $\mathrm{Pe}=0.1$ to 100,000 .

전혼합모델에서 유선경로모델로의 전이가 발생하였다. 이 는 Li (1995) 및 Stockman et al. (1997), Zafarani and Detwiler (2013)의 연구 결과와 일치한다. 그러나 $P e>$ 1,000에 대해서 Zafarani and Detwiler (2013)의 연구결과 와 다소 차이를 보인다. Zafarani and Detwiler (2013)의 연구결과는 $M_{r}$ 이 0 으로 수렴하여 완전 유선경로모델을 따르는 것으로 나타났지만, 본 연구결과는 $M_{r}$ 이 0.026 으
로 수렴하여 완전한 유선경로모델이 아닌 일부 용질의 혼합이 발생하는 것으로 나타났다. Stockman et al. (1997) 의 연구 결과는 $P e=1,547$ 에서의 $M_{r}=0.022$ 로 나타나 본 연구결과와 마찬가지로 높은 $P e$ 조건에서도 $M_{r}$ 이 0 으로 수렴하지 않는다는 연구결과를 제시하였다. 단열이 $90^{\circ}$ 로 교차하는 경우에 대한 본 연구결과는 이전 연구와 잘 일치하는 것으로 나타났다. 다소 연구결과의 차이가 


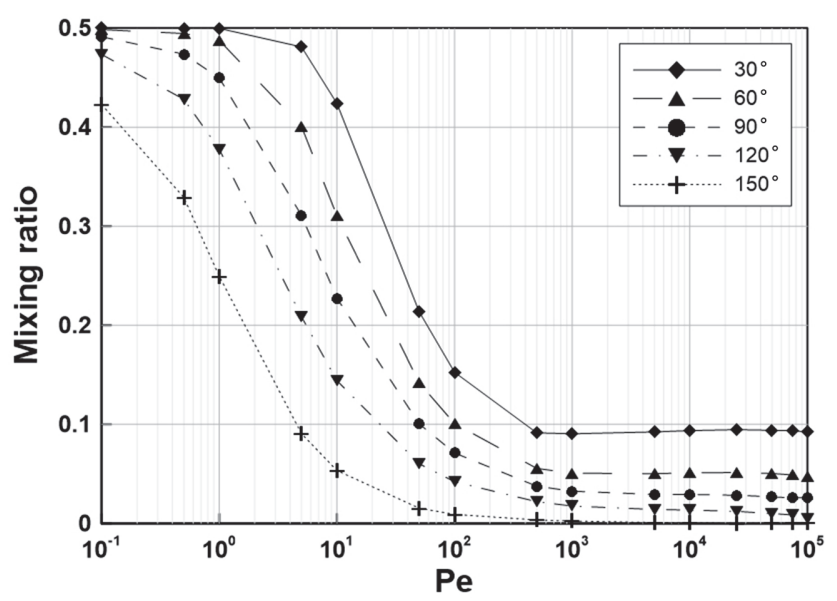

Fig. 7. Plots of mixing ratio $\left(\mathrm{M}_{\mathrm{r}}\right)$ versus $\mathrm{Pe}$ for various intersecting angles.

발생하는 이유는 기존 연구들의 경우 단열 내에서의 유 속분포 및 용질이동을 해석하는데 있어 다양한 가정을 통해 Navier-Stokes 방정식으로부터 유도된 단순화된 식 을 이용하여 근사한 반면, 본 연구에서는 Navier-Stokes 방정식과 용질이동방정식에 기반한 보다 정밀한 수치시 뮬레이션을 수행하였기 때문으로 판단된다.

\section{4. 결 론}

수치모델링을 통해 단열 교차점에서의 유동특성과 그 에 따른 용질의 혼합·분배 기작을 연구하였다. 완전혼합 모델과 유선경로모델의 상대적인 비율을 나타내는 지표 로 활용되는 용질의 혼합비율 $\left(M_{r}\right)$ 을 산정하여 단열의 교 차각과 유속조건에 따른 교차점에서 용질의 혼합과 분배 를 정량적으로 분석하였다.

단열의 교차각이 클수록 $M_{r}$ 이 작게 나타났다. 즉, 교차 각이 클 경우 유선경로에 따른 용질의 이동이 교차각이 작은 경우에 비해 상대적으로 더 발생하였다. 심지어 확 산이 지배적인 $P e<1$ 인 경우에도, 교차각이 큰 경우에 는 $100 \%$ 완전혼합이 일어나지 않았다. $P e=10$ 의 경우, 교차각이 클수록 $\left(\geqq 90^{\circ}\right)$ 유선을 따라 이동하는 유선경로 모델이 더 지배적이었으며, 교차각이 작을수록 $\left(<90^{\circ}\right)$ 완 전혼합모델이 더 지배적인 것으로 나타났다. 교차각이 $90^{\circ}$ 보다 큰 경우, 주입된 유체의 유동방향과 반대 방향의 유출구로 유출되기 때문에 양쪽 주입구에 온 유선들이 교차점에서 접촉하는 면적이 최소화 되면서 용질의 유선 경로모델이 더 지배적인 혼합·분배 모델이 된다. 반대로 교차각이 $90^{\circ}$ 보다 작은 경우, 유속과 같은 방향의 유출 구로 유출되기 때문에 양쪽 주입구에서 온 유선들이 교 차점에서 넓게 겹치게 되면서 용질 혼합이 일어나기 용
이하다.

$P e$ 가 0.1 - 100에서 완전혼합모델에서 유선경로모델로 전이되었지만, 이는 교차각에 따라 크게 달라졌다. 교차 각이 클수록 $\left(\geqq 150^{\circ}\right) P e=0.1-10$ 에서, 교차각이 작을 수록 $\left(\leqq 30^{\circ}\right) P e=10-100$ 에서 혼합.분배 모델의 전이 가 발생하였다. $P e>100$ 에서는 교차각과 상관없이 유선 경로모델이 더 지배적인 것으로 나타났다. $P e>1,000$ 에 서는 교차각이 $150^{\circ}$ 이상인 경우에만 $100 \%$ 유선경로모델 이 나타나며, 교차각이 $150^{\circ}$ 미만인 경우 일부 교차점에 서 용질의 혼합이 발생하였다. 교차각이 $30^{\circ}$ 인 경우 용 질의 혼합이 여전히 발생하며, 이로 인해 용질의 약 $10 \%$ 는 용질이 주입된 유선과 다른 단열로 유출되는 것으로 나타났다.

단열의 교차각은 교차점에서의 유동특성에 직접적인 영향을 미치는 것으로 분석되었으며, 교차점에서의 용질 의 혼합.분배 역시 이러한 유동특성과 밀접하게 관련되 는 것으로 나타났다. 동일한 $P e$ 조건에서 교차각이 클수 록 유선경로를 따라 이동하는 특성이 나타나며, 교차각 이 작을수록 혼합의 특성이 나타났다. 교차점에서의 용 질의 완전혼합모델과 유선경로모델의 비중은 $P e$ 뿐만이 아니라 교차각에 따라 결정되는 것으로 나타났다.

실제 암반 단열의 경우 교차각 이외에도 수리간극, 거 칠기 등의 다양한 기하학적 특징이 단열 교차점에서의 유동 특성에 유의미한 영향을 미칠 수 있어 이를 고려한 후속 연구가 필요할 것으로 판단된다. 최근 마이크로 입 자영상유속계(micro-particle image velocimetry) 등과 같 은 장비를 이용하여 마이크로 규모의 단열 내에서 유속 과 용질의 농도를 정밀하게 측정하는 방법들이 연구에 적용되고 있다. 따라서 이러한 측정 방법을 도입하여 현 상에 근거한 실험적 연구를 통해 단열 교차점에서의 혼 합·분배 모델을 검증할 필요가 있을 것으로 판단된다.

\section{사 사}

이 성과는 정부(과학기술정보통신부)의 재원으로 한국연 구재단의 지원을 받아 수행된 연구임(No. 2019R1F1A1058359).

\section{References}

Bear, J., Tsang, C.F. and de Marsily, G. (1993) Flow and Contaminant Transport in Fractured Rock. 1st(ed.), Academic Press, San Diego, 560p.

Berkowitz, B., Naumann, C. and Smith, L. (1994) Mass transfer at fracture intersections: an evaluation of mixing models, Water Resources Research, v.30(6), p.1765-1773, doi: 10.1029/ 94WR00432. 
Blessent, D., Therrien, R. and Gable, C.W. (2011) Large-scale numerical simulation of groundwater flow and solute transport in discretely-fractured crystalline bedrock, Advances in Water Resources, v.34(12), p.1539-1552, doi: 10.1016/j.advwatres. 2011.09.008.

Boutt, D.F., Grasselli, G., Fredrich, J.T., Cook, B.K. and Williams, J.R. (2006) Trapping zones: The effect of fracture roughness on the directional anisotropy of fluid flow and colloid transport in a single fracture. Geophysical Research Letters, v.33, doi:10.1029/ 2006GL027275.

Brush, D.J. and Thomson, N.R. (2003) Fluid flow in synthetic rough-walled fractures: Navier-Stokes, Stokes, and local cubic law simulations, Water Resources Research, v.39(4), doi: 10.1029/2002WR001346.

Cardenas, M.B., Slottke, D.T., Ketcham, R.A. and Sharp, J.M. Jr. (2007) Navier-Stokes flow and transport simulations using real fractures shows heavy tailing due to eddies. Geophysical Research Letters, v.34, doi:10.1029/2007GL030545.

Cardenas, M.B., Slottke, D.T., Ketcham, R.A. and Sharp, J.M. Jr. (2009) Effects of inertia and directionality on flow and transport in a rough asymmetric fracture, Journal of Geophysical Research, v.114, doi: 10.1029/2009JB006336.

Chaudhary, K., Cardenas, M.B., Deng, W. and Bennett, P.C. (2011) The role of eddies inside pores in the transition from Darcy to Forchheimer flows, Geophysical Research Letters, v.38(24), doi: 10.1029/2011GL050214.

COMSOL AB (2019). COMSOL Multiphysics Reference Manual version 5.5. Stockholm.

Dessirier, B., Frampton, A. and Jarsjo, J. (2015) A global sensitivity analysis of two-phase flow between fractured crystalline rock and bentonite with application to spent nuclear fuel disposal, Journal of Contaminant Hydrology, v.182, p.25-35, doi: 10.1016/ j.jconhyd.2015.07.006.

Detwiler, R., Rajaram, H. and Glass, R.J. (2000) Solute transport in variable-aperture fractures: An investigation of the relative importance of Taylor dispersion and macrodispersion, Water Resources Research, v.36(7), p.1611-1625, doi: 10.1029/ 2000WR900036.

Ji, S.H., Lee, H.B., Yeo, I.W. and Lee, K.K. (2008) Effect of nonlinear flow on DNAPL migration in a rough-walled fracture, Water Resources Research, v.44(11), doi: 10.1029/2007WR006712.

Lee, H.B., Yeo, I.W., Ji, S.H. and Lee, K.K. (2010) Wettabilitydependent DNAPL migration in a rough-walled fracture, Journal of Contaminant Hydrology, v.113(1-4), p.44-55, doi: 10.1016/ j.jconhyd.2009.12.006.

Lee, S.H., Lee, K.K. and Yeo, I.W. (2014) Assessment of the validity of Stokes and Reynolds equations for fluid flow through a rough-walled fracture with flow imaging, Geophysical Research Letters, v.42(13), p.4578-4585, doi: 10.1002/2014GL060481.

Lee, S.H., Yeo, I.W., Lee, K.K. and Detwiler, R.L. (2015) Tail shortening with developing eddies in a rough-walled rock fracture, Geophysical Research Letters, v.42(15), p.6340-6347, doi: 10.1002/2015GL065116.
Lee, S.H., Yeo, I.W., Lee, K.K. and Lee, S.L. (2017) The role of eddies in solute transport and recovery in rock fractures: Implication for groundwater remediation, Hydrological Processes, v.31(20), p.3580-3587. doi: 10.1002/hyp.11283.

Li, C. (1995) Low peclet number mixing behavior at fracture junctions. Ph.D thesis, New Mexico Institute of Mining and Technology.

Mourzenko, V.V., yousefian, F., Kolbah, B., Thovert, J.-F. and Adler, P.M. (2002) Solute transport at fracture intersections, Water Resources Research, v.38(1), p.1-14, doi: 10.1029/ 2000WR000211.

Neretnieks, I., Eriksen, T. and Tähtinen, P. (1982) Tracer movement in a single fissure in granitic rock: Some experimental results and their interpretation, Water Resources Research, v.18(4), p.849858, doi: 10.1029/WR018i004p00849.

Oron, A.P. and Berkowitz, B. (1998) Flow in rock fractures: The local cubic law assumption reexamined, Water Resources Research, v.34(33), p.2811-2825, doi: 10.1029/98WR02285.

Park, Y.J., de Dreuzy, J.R., Lee, K.K. and Berkowitz, B. (2001) Transport and intersection mixing in random fracture networks with power law length distributions, Water Resources Research, v.37(10), p.2493-2501, doi: 10.1029/2000WR000131.

Park, Y.J. and Lee, K.K. (1999) Analytical solutions for solute transfer characteristics at continuous fracture junctions, Water Resources Research. v.35(5), p.1531-1537, doi: 10.1029/ 1998WR900002.

Stockman, H.W., Li, C. and Wilson, J.L. (1997) A lattice-gas and lattice Boltzmann study of mixing at continuous fracture junctions: importance of boundary conditions, Geophysical Research Letters, v.24, p.1515-1518, doi: 10.1029/97GL51471.

Tsang, C.F., Neretnieks, I. and Tsang, Y. (2015) Hydrologic issues associated with nuclear waste repositories, Water Resources Research, v.51(9), p.6923-6972, doi: 10.1002/2015WR017641.

Zafarani, A. and Detwiler, R. L. (2013) An efficient time-domain approach for simulationg Pe-dependent transport through fracture intersection, Advances in Water Resources, v.53, p.198-207, doi: 10.1016/J.ADVWATRES.2012.11.011.

Zhang Z. and Nemcik, J. (2013). Fluid flow regimes and nonlinear flow characteristics in deformable rock fractures. Journal of Hydrology, v.477(16), 139-151, doi: 10.1016/j.jhydrol.2012.11.024.

Zhou, J.Q., Hu S.H., Fang, S., Chen, Y.F. and Zhou, C.B. (2015). Nonlinear flow behavior at low Reynolds numbers through rough-walled fractures subjected to normal compressive loading. International Journal of Rock Mechanics and Mining Sciences, v.80, p.202-218, doi: 10.1016/j.ijrmms.2015.09.027.

Zimmerman, R.W., Al-Yaarubi, A., Pain, C.C. and Grattoni, C.A. (2004). Non-linear regimes of fluid flow in rock fractures. International Journal of Rock Mechanics and Mining Sciences, v.41(1), p.163-169, doi: 10.1016/j.ijrmms.2004.03.036.

Zimmerman, R.W. and Yeo, I.W. (2000) Fluid flow in rock fractures: From the Navier-Stokes equations to the Cubic Law, Dynamics of Fluids in Fractured Rock, v.122, p.213-224, doi: 10.1029/GM122p0213. 